\title{
Evaluation of bronchial challenge test results for use in assessment of paediatric eczema: a retrospective series
}

\author{
KL Hon *, Abraham HY Ng, Chrystal CC Chan, Prisca XY Ho, Emma PM Tsoi, Kathy YC Tsang, \\ Fanny W Ko, TF Leung
}

\section{A B S T R A C T}

Background: Atopic dermatitis (AD), asthma, and allergic rhinitis are associated diseases involved in the atopic march. The bronchial challenge test (BCT) is a tool that evaluates airway hyperresponsiveness in patients with asthma. This study aimed to evaluate whether a positive BCT result is useful in assessment of paediatric $\mathrm{AD}$.

Methods: This retrospective case series included 284 patients with AD who had BCT results. Clinical information and laboratory parameters were reviewed, including AD severity (using the SCORing Atopic Dermatitis [SCORAD]), skin hydration, and transepidermal water loss.

Results: Of the 284 patients who had BCT, 106 had positive $\mathrm{BCT}$ results and 178 had negative $\mathrm{BCT}$ results. A positive $\mathrm{BCT}$ result was associated with a history of asthma $(\mathrm{P}<0.0005)$, sibling with asthma ( $\mathrm{P}=0.048)$, serum immunoglobulin $\mathrm{E} \quad(\mathrm{P}=0.045)$, eosinophil count $(\mathrm{P}=0.017)$, and sensitisation to food allergens in the skin prick test $(\mathrm{P}=0.027)$. There was no association between a positive $\mathrm{BCT}$ result and personal allergic rhinitis, parental atopy, sibling allergic rhinitis or $\mathrm{AD}$, skin prick response to dust mites, objective SCORAD score, skin hydration, transepidermal water loss, exposure to smoking,

This article was published on 4 Feb 2021 at www.hkmj.org. incense burning, cat or dog ownership, or AD treatment aspects (eg, food avoidance and traditional
Chinese medicine). Logistic regression showed significant associations of a positive BCT result with a history of asthma (adjusted odds ratio $=4.05$; 95\% confidence interval=1.92-8.55; $\quad \mathrm{P}<0.0005)$ and sibling atopy (adjusted odds ratio=2.25; 95\% confidence interval=1.03-4.92; $\mathrm{P}=0.042$ ).

Conclusions: In patients with paediatric AD, a positive $\mathrm{BCT}$ result was independently and positively associated with personal history of asthma and sibling history of atopy, but not with any other clinical parameters.

\section{Hong Kong Med J 2021;27:27-34}

https://doi.org/10.12809/hkmj208453

\author{
${ }^{1} \mathrm{KL}$ Hon *, MB, BS, MD \\ ${ }^{2} \mathrm{AHY} \mathrm{Ng}, \mathrm{MB}, \mathrm{ChB}$ \\ ${ }^{2}$ CCC Chan, MB, ChB \\ 2 PXY Ho, MB, ChB \\ ${ }^{2}$ EPM Tsoi, MB, ChB \\ ${ }^{1}$ KYC Tsang, MPhil, BSc \\ ${ }^{3} \mathrm{FW}$ Ko, MB, ChB, MD \\ ${ }^{1}$ TF Leung, MB, ChB, MD
}

Department of Paediatrics, The Chinese University of Hong Kong, Hong Kong

${ }^{2}$ Faculty of Medicine, The Chinese University of Hong Kong, Hong Kong

${ }^{3}$ Department of Medicine and Therapeutics, The Chinese University of Hong Kong, Hong Kong

* Corresponding author: ehon@hotmail.com

New knowledge added by this study

- In paediatric patients with atopic dermatitis (AD), a positive bronchial challenge test (BCT) result was significantly associated with a history of asthma (adjusted odds ratio $[\mathrm{aOR}]=4.05 ; 95 \%$ confidence interval $[\mathrm{CI}]=1.92-8.55 ; \mathrm{P}<0.0005)$ and sibling atopy $(\mathrm{aOR}=2.25 ; 95 \% \mathrm{CI}=1.03-4.92 ; \mathrm{P}=0.042)$.

- BCT results were independently and positively associated with a personal history of asthma and sibling history of asthma, but not with any other clinical parameters of AD.

Implications for clinical practice or policy

- BCT may have limited usefulness in patients with AD beyond the prediction of asthma prevalence or risk.

- Alternatives to the BCT should be sought with greater clinical predictive strength.

\section{Introduction}

Atopic dermatitis (AD) or eczema, asthma, and allergic rhinitis (AR) are associated diseases involved in the atopic march. ${ }^{1-3}$ Many children with AD develop asthma and/or AR when they reach adulthood. There are a number of clinical and laboratory tools to evaluate atopic status in patients with $\mathrm{AD}$. The bronchial challenge test (BCT) is an important tool that evaluates airway hyperresponsiveness in patients with asthma. Responsive patients develop acute contraction of smooth muscles lining the bronchi, resulting in sudden narrowing and obstruction of the airway. The extent of airway narrowing can increase during periods of exacerbation and decrease during 


\section{支氣管激發測試評估小兒濕疹：回顧系列研究 韓錦倫、吳希仁、何心悅、陳翠清、蔡柏雯、曾燕靜、 古惠珊、梁廷勳}

引言：異位性皮膚炎、哮喘和過敏性鼻炎是過敏進行曲常見的疾病 支氣管激發測試（BCT）是一種評估哮喘患者氣道高反應性的工具。 本研究旨在評估BCT陽性結果可否用於評估小兒異位性皮膚炎。

方法：這項回溯性系列病例研究納入284例具BCT結果的異位性皮膚 炎患者。回顧臨床信息和實驗室參數, 包括根據SCORAD評估的異位 性皮膚炎重度、皮膚水分和表皮水分流失。

結果：284例 BCT患者中，106例 BCT呈陽性，178例 BCT呈陰 性。BCT陽性結果與個人哮喘病史 $(\mathrm{P}<0.0005)$ 、兄弟姐妹哮喘病 史（ $\mathrm{P}=0.048 ） 、$ 血清免疫球蛋白 $\mathrm{E} （ \mathrm{P}=0.045 ）$ 、嗜酸性粒細胞數量 $(\mathrm{P}=0.017)$ 以及皮膚點刺測試診斷對食物過敏原敏感（ $\mathrm{P}=0.027 ）$ 呈相關。BCT陽性結果與以下因素無關, 包括過敏性鼻炎、父母過 敏、兄弟姐妹的過敏性鼻炎或異位性皮膚炎、皮膚點刺測試診斷對塵 螨敏感、客觀SCORAD評分、皮膚水分、表皮水分流失、吸煙、熏 香、貓狗飼養或異位性皮膚炎治療方面（如避免食物和中藥）。邏 輯迴歸分析顯示BCT陽性結果與個人哮喘病史（校正比值比 $=4.05$; 95\%置信區間1.92-8.55；P $<0.0005)$ 和兄弟姐妹過敏病史（校正比值 比=2.25；95\%置信區間1.03-4.92；P=0.042）顯著相關。

結論：在小兒異位性皮膚炎患者中, BCT陽性結果與個人哮喘病史和 兄弟姐妹過敏病史呈相關。
Distinct dosages are used for the inhalation of methacholine and histamine, but the inhalation challenge procedures are identical. ${ }^{8}$ During the test, a diluent is provided via nebulisation for five inhalations, followed by nebulisation of the test compound at low concentrations. A spirometry test is conducted after each dilution to assess the patient's pulmonary function. A reduction in forced expiratory volume in 1 second $\left(\mathrm{FEV}_{1}\right)$ of $\geq 20 \%$ signifies a positive response and the end of the test. A bronchodilator is then provided to counteract the effects of the test compound. In subsequent tests, the dose that provokes the desirable $\geq 20 \%$ reduction of $\mathrm{FEV}_{1}$ is employed. ${ }^{5}$

There are several contra-indications for the BCT. Patients with reduced lung function as evidenced by a low FEV level in baseline spirometry may be predisposed to a greater risk of serious adverse events. ${ }^{9}$ A prior bronchodilator $\mathrm{FEV}_{1}<60 \%$ predicted or $\mathrm{FEV}_{1}<75 \%$ predicted during a single high stimulus (eg, exercise) are relative contraindications. ${ }^{10}$ Airway obstruction in baseline spirometry supplemented with clinical features of asthma is sufficient for diagnosis and the BCT is unnecessary. Furthermore, an inability to follow the instructions of the spirometry test undermines the $\mathrm{BCT}$ quality. ${ }^{11}$ Individuals with a history of cardiovascular problems, increased intracranial pressure, or recent eye surgery may experience enhanced cardiovascular stress as a consequence of bronchoconstriction during the $\mathrm{BCT}$ and should not be subjected to this test. ${ }^{4,10}$ In general, patients with asthma respond to methacholine and histamine even at low concentrations, such that $84 \%$ and $73 \%$ react to the above compounds, respectively. ${ }^{12}$

This study aimed to investigate whether personal characteristics, history of allergen exposure, skin prick test results, clinical assessment scores, laboratory parameters, and personal or family histories of atopic diseases are associated with a positive BCT result in paediatric patients with AD. The result is useful in counselling parents and patients with $\mathrm{AD}$ and risks of asthma in the family.

\section{Methods}

This retrospective case series included patients with AD who were treated at the paediatric dermatology clinic of a university hospital from January 2000 to November 2017; patients who had undergone the BCT were retrospectively selected for analysis. All selected patients were Chinese and aged $>8$ years (the minimum age at which patients can complete the BCT in our hospital pulmonology laboratory)..$^{4,11,13}$ Data concerning the following clinical and personal characteristics were obtained from the patients' medical records: AD onset age, history of other atopy (ie, AR and atopic asthma), history of atopy (ie, $\mathrm{AD}$, atopic asthma and $\mathrm{AR}$ ) in parents and siblings, 
potential allergen exposure (ie, pet ownership and tobacco smoking), and AD treatment history (ie, allergen avoidance and use of traditional Chinese medicine). Clinical laboratory parameters obtained from the electronic patient record system included $\mathrm{BCT}$ results, highest serum IgE level, highest eosinophil counts (absolute and relative), and skin prick test results for allergic response to dust mite, cockroach, dogs, cats, and food allergens.

Atopic dermatitis severity was clinically scored by the SCORing Atopic Dermatitis (SCORAD), skin hydration, and transepidermal water loss (TEWL) during follow-up visits. ${ }^{14}$ The SCORAD is a mathematically derived score that considers the extent, severity, and subjective symptoms of AD. ${ }^{15}$ The skin hydration and TEWL were measured using Courage and Khazaka equipment, which indirectly measures the density gradient of water evaporation from the skin by two pairs of sensors that determine the temperature and relative humidity, respectively. ${ }^{16}$

The IBM SPSS Statistics (Windows version 20) was used to conduct all statistical analysis. Student's $t$ test was conducted to compare continuous variables between groups; these data were expressed as mean \pm standard deviation. The Chi squared test (or Fisher's exact test) was conducted to compare categorical variables between groups; these data were expressed as number (\%). A P value of $<0.05$ was considered statistically significant. Backward binary logistic regression analysis was then used to analyse the data. The variable with the highest $P$ value was removed at each step until the final equation included only variables with $\mathrm{P}<0.05$.

The New Territories East Cluster and The Chinese University of Hong Kong ethics committee approved this retrospective study.

\section{Results}

\section{Overall patient characteristics}

In total, 579 patients with $\mathrm{AD}$ were included in this study; 284 had confirmed BCT results. Patient follow-up data were censored as of November 2017 to February 2018. Of the 284 patients with BCT results, 106 had a positive result (BCT-positive group), while 178 had a negative result (BCT-negative group). There were significant differences in current age $(\mathrm{P}=0.039)$ and the age at $\mathrm{BCT}$ performance $(\mathrm{P}=0.004)$ between groups (Table 1 ).

\section{Personal and family histories of atopic diseases}

A positive $\mathrm{BCT}$ result was associated with personal history of asthma $(\mathrm{P}<0.0005)$ and a sibling with asthma, compared with patients with a negative $\mathrm{BCT}$ result (28.6\% vs $6.8 \% ; \mathrm{P}=0.048)$ [Table 1 ].

There were no significant associations between $\mathrm{BCT}$ results and personal AR, maternal atopy (specifically, asthma, AR, AD), paternal atopy (specifically asthma, AR, AD), siblings' AR, and siblings' AD. Moreover, BCT results were not associated with a history of skin prick response to allergens, including dust mites (Table 1).

\section{Clinical measures, laboratory results, environmental factors, and previous treatment}

There were no significant associations between $\mathrm{BCT}$ results and clinical measures of $\mathrm{AD}$ severity, in terms of objective SCORAD score, SH, or TEWL. Results of BCT were associated with markers of allergic reactions, including (highest) serum IgE ( $\mathrm{P}=0.045)$, highest eosinophil count $(\mathrm{P}=0.017)$, and sensitisation to food allergens in skin prick test $(\mathrm{P}=0.027)$. However, they were not associated with other allergens tested in the skin prick panel, such as aeroallergens from dust mites, cockroaches, dogs, or cats (Table 1). Results of BCT had no significant association with previous exposure to potential environmental irritants, including smoking in the household, incense burning, cat ownership, or dog ownership. There were no significant associations between BCT results and history of AD treatment, including food avoidance and traditional Chinese medicine usage (Table 1).

\section{Regression analysis}

Of the 284 patients with $\mathrm{AD}$ and confirmed BCT results, 142 patients had all relevant data available. Backward binary logistic regression $(n=142)$ showed significant associations between a positive BCT result and a personal history of asthma (adjusted odds ratio $[\mathrm{aOR}]=4.05 ; 95 \%$ confidence interval $[C I]=1.92-8.55 ; \quad \mathrm{P}<0.0005)$ and sibling atopy $(\mathrm{aOR}=2.25 ; 95 \% \mathrm{CI}=1.03-4.92 ; \mathrm{P}=0.042)$. However, it did not show associations with AD severity, young age at $\mathrm{AD}$ onset, personal history of $\mathrm{AR}$, aeroallergen (including dust mite, cockroach, cat and dog hair) and food allergen sensitisation, parental history of atopy, or highest serum IgE level and blood eosinophil count (Table 2).

\section{Discussion}

\section{Atopic dermatitis and asthma}

In our study, backward binary logistic regression analysis showed that a positive BCT result was independently and positively associated with a personal history of asthma in patients with AD. The Global Initiative for Asthma, a medical guidelines organisation, has established a standard for the diagnosis of asthma, which recommends the documentation of variable expiratory airflow limitation. Although asthma is principally a clinical diagnosis, the BCT can aid in this assessment. ${ }^{17}$ The sensitivity of the BCT in complementing asthma 
TABLE I. Demographics of patients with AD, stratified according to BCT results $(n=284)^{*}$

\begin{tabular}{|c|c|c|c|}
\hline & BCT positive $(n=106)$ & BCT negative $(n=178)$ & $P$ value \\
\hline \multicolumn{4}{|l|}{ Patient characteristics } \\
\hline Current age $\pm S D$, years & $20.7 \pm 4.1$ & $21.7 \pm 4.1$ & 0.039 \\
\hline Male & $61(57.5 \%)$ & $92(51.7 \%)$ & 0.338 \\
\hline Onset age, years $(n=256)$ & $2.1 \pm 2.9(n=93)$ & $2.8 \pm 3.6(n=163)$ & 0.098 \\
\hline Age at $\mathrm{BCT}$, years & $12.1 \pm 3.5$ & $13.4 \pm 3.6$ & 0.004 \\
\hline Prematurity $(n=140)$ & $1(2.0 \%)$ & $3(3.3 \%)$ & $>0.999 \dagger$ \\
\hline Asthma positive $(\mathrm{n}=271)$ & $64(63.4 \%)$ & $63(37.1 \%)$ & $<0.0005$ \\
\hline Allergic rhinitis positive $(n=277)$ & $90(86.5 \%)$ & $135(78.0 \%)$ & 0.079 \\
\hline Maternal atopy positive $(n=269)$ & $38(40.0 \%)$ & $71(40.8 \%)$ & 0.898 \\
\hline Maternal asthma $(n=65)$ & $1(4.8 \%)$ & $2(4.5 \%)$ & $>0.999 \dagger$ \\
\hline Maternal allergic rhinitis $(n=65)$ & $5(23.8 \%)$ & $13(29.5 \%)$ & 0.629 \\
\hline Maternal AD (n=65) & $3(14.3 \%)$ & $7(15.9 \%)$ & $>0.999 \dagger$ \\
\hline Paternal atopy positive $(n=270)$ & $51(53.7 \%)$ & $91(52.0 \%)$ & 0.791 \\
\hline Paternal asthma $(n=68)$ & 0 & $4(8.7 \%)$ & $0.296 \dagger$ \\
\hline Paternal allergic rhinitis $(n=68)$ & $6(27.3 \%)$ & $14(30.4 \%)$ & 0.789 \\
\hline Paternal AD (n=67) & $2(9.1 \%)$ & $8(17.8 \%)$ & $0.478 \dagger$ \\
\hline Sibling atopy positive $(n=261)$ & $59(64.1 \%)$ & $89(52.7 \%)$ & 0.074 \\
\hline Sibling asthma $(n=65)$ & $6(28.6 \%)$ & $3(6.8 \%)$ & $0.048 \dagger$ \\
\hline Sibling allergic rhinitis $(n=65)$ & $8(38.1 \%)$ & $12(27.3 \%)$ & 0.377 \\
\hline Sibling AD ( $n=65)$ & $9(42.9 \%)$ & $12(27.3 \%)$ & 0.209 \\
\hline \multicolumn{4}{|l|}{ Clinical measures for $A D$} \\
\hline Objective SCORAD score $(n=198)$ & $28.4 \pm 17.0(n=70)$ & $27.4 \pm 15.3(n=128)$ & 0.677 \\
\hline $\mathrm{SH}(n=182)$ & $30.3 \pm 12.7(n=71)$ & $32.6 \pm 12.1(n=111)$ & 0.227 \\
\hline TEWL $(n=182)$ & $10.7 \pm 7.0(n=71)$ & $10.0 \pm 6.0(n=111)$ & 0.503 \\
\hline \multicolumn{4}{|l|}{ Laboratory investigations } \\
\hline Highest serum IgE level, IU/mL (n=223) & $7962 \pm 11046(n=81)$ & $5133 \pm 7941(n=142)$ & 0.045 \\
\hline Highest eosinophil count, 109/L ( $n=248)$ & $0.96 \pm 0.88(n=89)$ & $0.71 \pm 0.75(n=159)$ & 0.017 \\
\hline \multicolumn{4}{|l|}{ Skin prick test result } \\
\hline Dust mite positive $(\mathrm{n}=282)$ & $101(96.2 \%)$ & $166(93.8 \%)$ & 0.384 \\
\hline Cockroach positive $(n=281)$ & $48(45.7 \%)$ & $60(34.1 \%)$ & 0.053 \\
\hline Dog positive $(n=282)$ & $20(19.0 \%)$ & $23(13.0 \%)$ & 0.172 \\
\hline Cat positive $(n=282)$ & $41(39.0 \%)$ & $67(37.9 \%)$ & 0.842 \\
\hline Food allergen(s) positive $(n=281)$ & 78 (74.3\%) & $108(61.4 \%)$ & 0.027 \\
\hline \multicolumn{4}{|l|}{ Environmental factors } \\
\hline Smoking exposure $(n=244)$ & $19(21.3 \%)$ & $34(21.9 \%)$ & 0.915 \\
\hline Cat exposure $(n=260)$ & $2(2.1 \%)$ & $4(2.4 \%)$ & $>0.999 \dagger$ \\
\hline Dog exposure $(n=260)$ & $7(7.4 \%)$ & $9(5.5 \%)$ & 0.536 \\
\hline \multicolumn{4}{|l|}{ Previous treatment for $A D$} \\
\hline Any TCM $(n=264)$ & $64(66.0 \%)$ & $101(60.5 \%)$ & 0.373 \\
\hline Any food avoidance $(n=264)$ & 68 (72.3\%) & 125 (73.5\%) & 0.835 \\
\hline
\end{tabular}

Abbreviations: $\mathrm{AD}=$ atopic dermatitis; $\mathrm{BCT}=$ bronchial challenge test; $\lg \mathrm{E}=$ immunoglobulin $\mathrm{E} ; \mathrm{SCORAD}=\mathrm{SCORing}$ Atopic Dermatitis; $\mathrm{SD}=$ standard deviation; $\mathrm{TCM}=$ traditional Chinese medicine; TEWL = transepidermal water loss

* Continuous data are shown as mean \pm standard deviation and compared by $t$ test; categorical data are shown as No. (\%) and compared by Chi squared test or Fisher's exact test

† Totals may not be 284 because some data are unavailable 
diagnosis is generally believed to approach $100 \%$ if a cut point is set at $8 \mathrm{mg} / \mathrm{mL}$ or $16 \mathrm{mg} / \mathrm{mL}$, using a non-deep inhalation method. ${ }^{18}$ Cockcroft $^{18}$ showed that when the PC20 (ie, histamine provocative concentration causing a $20 \%$ drop in $\mathrm{FEV}_{1}$ ) cut-off was set at $\leq 8 \mathrm{mg} / \mathrm{mL}$, all individuals with current symptomatic asthma could be identified in a random population with a sensitivity of nearly $100 \%{ }^{1}$

However, a recent study indicated that the prevalence of a positive $\mathrm{BCT}$ result in children with asthma is approximately $70 \%{ }^{19}$ This is attributed to the potential effects of several factors associated with a positive BCT result, especially using the methacholine challenge test; these factors include $\mathrm{AR}$, respiratory infections, and chronic respiratory conditions (eg, bronchitis and chronic obstructive pulmonary disease). ${ }^{19}$ Despite its limitations, including that the test can only be used in older children, the $\mathrm{BCT}$ remains a useful tool for the diagnosis of asthma (Table 2). Clinical usage of the BCT in the diagnosis of asthma is based on its high sensitivity and negative predictive value, but a positive $\mathrm{BCT}$ result itself is not confirmatory for asthma. ${ }^{17,20}$

In this study of 284 patients with $\mathrm{BCT}$ results, the aOR of a positive BCT result for asthma in patients with $\mathrm{AD}$ was 4.05 , implying that patients with $\mathrm{AD}$ who have a positive $\mathrm{BCT}$ result are fourfold more likely to have asthma. This is consistent with the findings of a 2015 meta-analysis that included 31 studies conducted in 102 countries; the risk ratio of $\mathrm{AD}$ to other two atopic disorders, including $\mathrm{AR}$ and asthma, was 4.24 (95\% CI=3.75-4.79). The results demonstrated a clear relationship between the skin and the airways. ${ }^{21}$ Riiser et $\mathrm{al}^{22}$ followed 530 children who completed the $\mathrm{BCT}$ at the age of 10 years and underwent structured reviews and clinical examinations at the age of 16 years; they examined the predictability of BCT results for active asthma in adolescence. The investigators concluded that the presence of bronchial hyperreactivity (BHR), especially severe BHR, was a significant risk factor and that provocative dose 20 resulting in $20 \%$ decrease in $\mathrm{FEV}_{1}$ in a positive test alone explained $10 \%$ of the variation in active asthma. ${ }^{22}$ Another study showed similar findings, in that airway hyperresponsiveness independently predicted asthma symptoms in childhood $(\mathrm{aOR}=2.6$; 95\% CI=1.8-3.7). ${ }^{23}$ Our results concurred with those of the above studies, indicating that BHR could develop before active asthma symptoms appear and that BCT might indeed predict asthma incidence in children with AD.

\section{Sibling history of atopy}

Atopy is known to have a strong hereditary component. A family study of 188 Caucasian patients and their family members demonstrated a twofold
TABLE 2. Clinical asthma diagnosis and bronchial challenge test $(B C T)$ status $(n=27 I)$

\begin{tabular}{lcc}
\hline & Asthma positive $(\mathbf{n}=\mathbf{1 2 7})$ & Asthma negative $(\mathbf{n}=\mathbf{1 4 4})$ \\
\hline BCT positive $(n=101)$ & True positive: 64 & False positive: 37 \\
BCT negative $(n=170)$ & False negative: 63 & True negative: 107 \\
\hline
\end{tabular}

Sensitivity of BCT = true positive/asthma positive $=50.4 \%$

Specificity of BCT $=$ true negative/asthma negative $=74.3 \%$

Positive predictive value $=$ true positive/BCT positive $=63.4 \%$

Negative predictive value $=$ true negative/BCT negative $=62.9 \%$

increase in risk of developing $\mathrm{AD}$ and atopy with each additional first-degree relative who exhibited atopy. ${ }^{24}$ Furthermore, a maternal history of atopic disease was associated with an elevated IgE level among infants. For maternal asthma, this association was only evident in infant girls. ${ }^{25}$ Hong Kong has a relatively high prevalence of single-child families; however, among patients with siblings, positive relationships with sibling atopy have been found. ${ }^{1,2}$ In our study, among 106 patients with a positive $\mathrm{BCT}$ result, rates of maternal, paternal, and sibling atopy were $40.0 \%, 53.7 \%$, and $64.1 \%$, respectively. A positive $\mathrm{BCT}$ result was independently and positively associated with sibling atopy $(\mathrm{aOR}=2.25$; 95\% $\mathrm{CI}=1.03-4.92 ; \quad \mathrm{P}=0.042)$, which includes asthma, AR, and/or AD. However, no associations with parental atopy were found. Patients with positive $\mathrm{BCT}$ results are presumably more likely to have siblings with atopy, in that $64.1 \%$ of patients with positive BCT results had siblings with atopy, compared with $52.7 \%$ of patients with negative $\mathrm{BCT}$ results. The most likely explanations of the association with siblings involve genetic heredity and similar epigenetic factors in childhood. Siblings of patients with atopy are predisposed to an inherited tendency to developing IgE antibodies to specific allergens, with subsequent hypersensitivity reactions. Several twin studies were conducted to demonstrate the roles of genetic and environmental factors on atopy. A multivariate genetic analysis with a total of 575 twin participants revealed that atopic conditions were associated with genetic and environmental factors; it also showed that different phenotypic conditions shared common genetic backgrounds. ${ }^{26}$ Family and twin studies have shown that genetic inheritance plays an important role in the development of atopy; they identified 79 genes associated with asthma or atopy in more than one population. ${ }^{27}$ Despite genetic involvement, atopic conditions are highly heterogeneous and involve complex epigenetic factors. The atopic state is presumably related to a pre-existing genotype that is activated by environmental factors. ${ }^{28}$ Both the factors themselves and duration of exposure are important. Several epigenetic factors with an impact on atopy have been established; these can be further subcategorised into prenatal, infancy, childhood, 
and adulthood types. ${ }^{29}$ Affected children and their siblings are exposed to common environmental factors in their childhood, such as tobacco smoke, allergic sensitisation, infections, and diet.

There was minimal information concerning birth order and family size in the present study, although these factors may have substantial impacts on allergic disease susceptibility. Asthma prevalence is reportedly inversely related to family size in families with $\geq 4$ children. ${ }^{30}$ An inverse relationship between birth order and asthma risk has also been suggested. Compared with younger siblings, stronger associations with older siblings with asthma have been demonstrated. ${ }^{30}$ However, family size was not specified in those studies; thus, there is a need to determine whether family size or birth order exerts a greater impact upon the risk of atopy. The mechanism by which younger children are protected against atopy is unknown. One possible explanation is the hygiene hypothesis, which suggests that children with less exposure to pathogens and other microorganisms in early childhood are more susceptible to allergic diseases. An implication is that the attempt to create dust-free and pathogenfree clean environment leads to increased atopy prevalence. The presence of older siblings and larger family size is presumed to protect children from atopy through greater exposure in early childhood, thus modulating their immune systems.

\section{Food and aeroallergen sensitisation}

Univariate analysis showed that food sensitisation, but not aeroallergen sensitisation, was significantly associated with a positive $B C T$ result in patients with $\mathrm{AD}(\mathrm{P}=0.027)$. The association was not statistically significant following regression analysis. It has been reported that $40 \%$ of patients with food allergy, but no diagnosis of asthma, have a substantial degree of bronchial hyperactivity (measured by the BCT) ${ }^{31}$ Another small study $(\mathrm{n}=22$ patients with allergic asthma) showed no relationship between skin prick test sensitisation and inhaled reactivity (measured by the methacholine BCT). ${ }^{32}$ Skin allergen sensitisation does not accurately predict airway allergen response. ${ }^{32,33}$ This result was confirmed by several other studies, ${ }^{34,35}$ which showed no relationship between methacholine responsiveness and the presence or degree of atopy. Hence, food and aeroallergen sensitisation are generally not associated with $\mathrm{BCT}$ results.

\section{Serum immunoglobulin E level and blood eosinophil count}

Univariate analysis showed significant associations of serum IgE level $(\mathrm{P}=0.045)$ and blood eosinophil count $(\mathrm{P}=0.017)$ with a positive $\mathrm{BCT}$ result. These findings were consistent with the results published by Liu et $\mathrm{al}^{36}$ concerning significant relationships of BHR to methacholine and increased total serum IgE to a positive $B C T$ result $(\mathrm{P}=0.001)$. Sears et $\mathrm{al}^{37}$ showed that BHR was related to serum IgE level in children not diagnosed with asthma; this relationship persisted despite the exclusion of children with a history of AR or AD. Hence, BHR is dependent on serum IgE level and is unrelated to the presence of AD. Nevertheless, IgE can be measured in young children when BHR is difficult to demonstrate; notably, IgE is a simple blood marker of AD severity and asthma risk. ${ }^{7,38}$

\section{Personal history of allergic rhinitis}

The "one airway" hypothesis (ie, "united airway disease") is based on the bidirectional interaction between asthma and rhinitis, with the implication that both upper and lower airways should be treated for optimal symptomatic control. ${ }^{39,40}$ However, our study showed no association between the presence of $A R$ and a positive $B C T$ result in children with $\mathrm{AD}(\mathrm{P}=0.079)$. Although several studies have shown an association between AR and BHR, they did not equate a positive BCT result with the diagnosis of AR. ${ }^{20,41,42}$

\section{Atopic dermatitis severity}

In our study, there was no association between $\mathrm{AD}$ severity (based on objective SCORAD score, SH, and TEWL) and a positive BCT result. Liu et $\mathrm{al}^{36}$ found that BHR to methacholine was related to atopy $(\mathrm{P}=0.0063)$, while the degree of BHR was not significantly associated with the severity of any atopic disease.

\section{Strengths and limitations of this study}

The strengths of this study included collection and review of the data over 10 years, which enabled the addition of follow-up assessments for many of the patients. The Prince of Wales Hospital is a public hospital; the family cost of healthcare service is relatively low, which supports a low dropout rate and consistent long-term follow-up. Our relatively large sample size enabled examination of various atopic phenotypes. Patients with AD who exhibited both skin and airway manifestations confirm the presumed atopic march with progression from $A D$ to AR and asthma, or co-expression of asthma and AD phenotypes (ie, skin sensitivity plus wheeze).

The primary limitation of the present study was that data were missing for some factors, notably family atopic conditions and laboratory tests. Regarding the family history, many parents did not provide clear information concerning their own atopic conditions. Those with mild symptoms may fail to seek medical advice, although they reported self-diagnosed atopic conditions. Although only physician-diagnosed conditions were included in 
the data analysis, there was difficulty confirming the validity of those family histories. A substantial number of patients were only children in their families and had no siblings. Additionally, the BCT is a medical test that provokes airway narrowing. It is physically demanding and can cause severe discomfort (eg, violent coughing) which makes the measurement difficult. The irritating nature of the BCT makes it suitable solely for older children and causes high failure rates; thus, the number of patients with a positive BCT result was relatively low. Our observations concerning the usefulness of the BCT should be confirmed in a prospective study.

\section{Conclusions}

In patients with paediatric $\mathrm{AD}$, a positive $\mathrm{BCT}$ result was independently and positively associated with personal history of asthma and sibling history of atopy, but not with any other clinical parameters.

\section{Author contributions}

Concept or design: KL Hon, AHY Ng, CCC Chan, PXY Ho, EPM Tsoi, TF Leung.

Acquisition of data: AHY Ng, CCC Chan, PXY Ho, EPM Tsoi. Analysis or interpretation of data: KL Hon, AHY Ng, CCC Chan, PXY Ho, EPM Tsoi, KYC Tsang.

Drafting of the manuscript: KL Hon, AHY Ng, CCC Chan, PXY Ho, EPM Tsoi, FW Ko.

Critical revision of the manuscript for important intellectual content: KL Hon, FW Ko, TF Leung.

\section{Conflicts of interest}

As the editor of the journal, KL Hon was not involved in the peer review process. Other authors have disclosed no conflicts of interest.

\section{Funding/support}

This research received no specific grant from any funding agency in the public, commercial, or not-for-profit sectors.

\section{Ethics approval}

This study was approved by The Joint Chinese University of Hong Kong-New Territories East Cluster Clinical Research Ethics Committee (The Joint CUHK-NTEC CREC).

\section{References}

1. Hon KL, Liu M, Zee B. Airway disease and environmental aeroallergens in eczematics approaching adulthood. Pediatr Respirol Crit Care Med 2017;1:81-5.

2. Hon KL, Wang SS, Leung TF. The atopic march: from skin to the airways. Iran J Allergy Asthma Immunol 2012;11:737.

3. Hon KL, Yong V, Leung TF. Research statistics in atopic eczema: what disease is this? Ital J Pediatr 2012;38:26.

4. Coates AL, Wanger J, Cockcroft DW, et al. ERS technical standard on bronchial challenge testing: general considerations and performance of methacholine challenge tests. Eur Respir J 2017;49:1601526.

5. Dixon $C$. The bronchial challenge test: a new direction in asthmatic management. J Natl Med Assoc 1983;75:199204.

6. Pepys J, Hutchcroft BJ. Bronchial provocation tests in etiologic diagnosis and analysis of asthma. Am Rev Respir Dis 1975;112:829-59.

7. Ng C, Hon KL, Kung JS, Pong NH, Leung TF, Wong CK. Hyper IgE in childhood eczema and risk of asthma in Chinese children. Molecules 2016;21:E753.

8. Miller MR, Crapo R, Hankinson J, et al. General considerations for lung function testing. Eur Respir J 2005;26:153-61.

9. Ramsdale EH, Morris MM, Roberts RS, Hargreave FE. Bronchial responsiveness to methacholine in chronic bronchitis: relationship to airflow obstruction and cold air responsiveness. Thorax 1984;39:912-8.

10. Crapo RO, Casaburi R, Coates AL, et al. Guidelines for methacholine and exercise challenge testing-1999. This official statement of the American Thoracic Society was adopted by the ATS Board of Directors, July 1999. Am J Respir Crit Care Med 2000;161:309-29.

11. Miller MR, Hankinson J, Brusasco V, et al. Standardisation of spirometry. Eur Respir J 2005;26:319-38.

12. Spector SL, Farr RS. A comparison of methacholine and histamine inhalations in asthmatics. J Allergy Clin Immunol 1975;56:308-16.

13. Schulze J, Smith HJ, Fuchs J, et al. Methacholine challenge in young children as evaluated by spirometry and impulse oscillometry. Respir Med 2012;106:627-34.

14. Hon KL, Kung JS, Tsang KY, Yu JW, Cheng NS, Leung TF. Do we need another symptom score for childhood eczema? J Dermatolog Treat 2018;29:510-4.

15. Severity scoring of atopic dermatitis: the SCORAD index. Consensus Report of the European Task Force on Atopic Dermatitis [editorial]. Dermatology 1993;186:23-31.

16. Hon KL, Wong KY, Leung TF, Chow CM, Ng PC. Comparison of skin hydration evaluation sites and correlations among skin hydration, transepidermal water loss, SCORAD index, Nottingham eczema severity score, and quality of life in patients with atopic dermatitis. Am J Clin Dermatol 2008;9:45-50.

17. Rothe T, Spagnolo P, Bridevaux PO, et al. Diagnosis and management of asthma-the Swiss guidelines. Respiration 2018;95:364-80.

18. Cockcroft DW. Direct challenge tests: Airway hyperresponsiveness in asthma: its measurement and clinical significance. Chest 2010;138(2 Suppl):18S-24S.

19. Huang SJ, Lin LL, Chen LC, et al. Prevalence of airway hyperresponsiveness and its seasonal variation in children with asthma. Pediatr Neonatol 201;59:561-6.

20. Davis BE, Cockcroft DW. Past, present and future uses of methacholine testing. Expert Rev Respir Med 2012;6:3219.

21. Pols DH, Wartna JB, van Alphen EI, et al. Interrelationships between atopic disorders in children: a meta-analysis based on ISAAC questionnaires. PLoS One 2015;10:e0131869.

22. Riiser A, Hovland V, Carlsen KH, Mowinckel P, Lødrup Carlsen $\mathrm{KC}$. Does bronchial hyperresponsiveness in childhood predict active asthma in adolescence? Am J Respir Crit Care Med 2012;186:493-500.

23. Toelle BG, Xuan W, Peat JK, Marks GB. Childhood factors that predict asthma in young adulthood. Eur Respir J 2004;23:66-70.

24. Küster W, Petersen M, Christophers E, Goos M, Sterry W. 
A family study of atopic dermatitis. Clinical and genetic characteristics of 188 patients and 2151 family members. Arch Dermatol Res 1990;282:98-102.

25. Johnson CC, Ownby DR, Peterson EL. Parental history of atopic disease and concentration of cord blood IgE. Clin Exp Allergy 1996;26:624-9.

26. Thomsen SF, Ulrik CS, Kyvik KO, Ferreira MA, Backer V. Multivariate genetic analysis of atopy phenotypes in a selected sample of twins. Clin Exp Allergy 2006;36:138290.

27. Ober C, Hoffjan S. Asthma genetics 2006: the long and winding road to gene discovery. Genes Immun 2006; 7:95100.

28. Sublett JL. The environment and risk factors for atopy. Curr Allergy Asthma Rep 2005;5:445-50.

29. Subbarao P, Mandhane PJ, Sears MR. Asthma: epidemiology, etiology and risk factors. CMAJ 2009;181:E181-90.

30. Goldberg S, Israeli E, Schwartz S, et al. Asthma prevalence, family size, and birth order. Chest 2007;131:1747-52.

31. Kivity S, Fireman E, Sade K. Bronchial hyperactivity, sputum analysis and skin prick test to inhalant allergens in patients with symptomatic food hypersensitivity. Isr Med Assoc J 2005;7:781-4.

32. Bowton DL, Fasano MB, Bass DA. Skin sensitivity to allergen does not accurately predict airway response to allergen. Ann Allergy Asthma Immunol 1998;80:207-11.

33. Turner KJ, Stewart GA, Woolcock AJ, Green W, Alpers MP. Relationship between mite densities and the prevalence of asthma: comparative studies in two populations in the Eastern Highlands of Papua New Guinea. Clin Allergy 1988;18:331-40.

34. Lúdvíksdóttir D, Janson C, Björnsson E, et al. Different airway responsiveness profiles in atopic asthma, nonatopic asthma, and Sjögren's syndrome. BHR Study Group. Bronchial hyperresponsiveness. Allergy 2000;55:259-65.

35. Suh DI, Lee JK, Kim CK, Koh YY. Methacholine and adenosine 5'-monophosphate (AMP) responsiveness, and the presence and degree of atopy in children with asthma. Pediatr Allergy Immunol 2011;22:e101-6.

36. Liu SF, Lin MC, Chang HW. Relationship of allergic degree and $\mathrm{PC} 20$ level in adults with positive methacholine challenge test. Respiration 2005;72:612-6.

37. Sears MR, Burrows B, Flannery EM, Herbison GP, Hewitt CJ, Holdaway MD. Relation between airway responsiveness and serum IgE in children with asthma and in apparently normal children. $\mathrm{N}$ Engl J Med 1991;325:1067-71.

38. Hon KL, Lam MC, Leung TF, et al. Are age-specific high serum IgE levels associated with worse symptomatology in children with atopic dermatitis? Int J Dermatol 2007;46:1258-62.

39. Haccuria A, Van Muylem A, Malinovschi A, Doan V, Michils A. Small airways dysfunction: the link between allergic rhinitis and allergic asthma. Eur Respir J 2018;51:1701749.

40. Lluncor M, Barranco P, Amaya ED, et al. Relationship between upper airway diseases, exhaled nitric oxide, and bronchial hyperresponsiveness to methacholine. J Asthma 2019;56:53-60.

41. Shaaban R, Zureik M, Soussan D, et al. Allergic rhinitis and onset of bronchial hyperresponsiveness. Am J Respir Crit Care Med 2007;176:659-66.

42. Ciprandi G, Signori A, Cirillo I. Relationship between bronchial hyperreactivity and bronchodilation in patients with allergic rhinitis. Ann Allergy Asthma Immunol 2011;106:460-6. 